\title{
A prospective study of acute idiopathic neuropathy. I. Clinical features and their prognostic value
}

\author{
J B WINER, * R A C HUGHES, * C OSMOND $\dagger$ \\ From the Department of Neurology, ${ }^{*}$ United Medical and Dental Schools, Guy's Hospital, London and MRC \\ Environmental Epidemiology Unit, $\dagger$ University of Southampton, Southampton, UK
}

SUMmARY A prospective study in South-East England during 15 months in 1983-1984 recruited 100 patients with acute idiopathic neuropathy. After 12 months $67 \%$ had recovered completely, $20 \%$ were still significantly disabled and $13 \%$ had died. Ten of the 13 deaths were attributable to the neuropathy. The major features in the initial assessment which were associated with persistent disability were the time taken to become bedbound, requirement for ventilation, age greater than $\mathbf{4 0}$ years, and small or absent compound abductor pollicis brevis muscle action potentials elicited by stimulation of the median nerve at the wrist. These four variables have been combined in a statistical model to predict outcome for individual patients with acute idiopathic neuropathy.

Although the majority of patients with Guillain-Barré syndrome make an acceptable functional recovery, a proportion succumb to the acute illness while others retain significant residual disability. ${ }^{1}$ It is difficult to estimate how many patients remain disabled from the literature. No large scale prospective study has ever been carried out and the available retrospective studies give an incomplete picture of outcome. Data have been collected prospectively on 100 patients who were thought on presentation to have Guillain-Barré syndrome and the group followed for 12 months. Clinical and laboratory features at presentation are analysed for their value in predicting outcome.

\section{Patients and methods}

Clinical study Neurologists within the four Thames Regional Health Authorities were notified of our prospective study of acute idiopathic neuropathy and permission sought to survey patients. Ethical approval was obtained from the National Hospitals for Nervous Diseases and Guy`s Hospital. The Lancet and the British Medical Journal published short letters requesting permission to survey patients in district general hospitals under the care of general physicians alone.

All the eligible patients who came to our notice from September 1983 until December 1984 were admitted to the study. Ninety-one patients came from hospitals within the four Thames Health Regions, six from Wessex, two from

Address for reprint requests: $\operatorname{Dr}$ J B Winer, Department of Neurology, St Mary's Hospital, Praed Street, London W2 INY, UK.

Received 7 August 1987 and in revised form 18 November 1987. Accepted 24 November 1987
East Anglia and one from Trent Health Region. The population of the Thames Health Regions is about 13.7 million.

New patients were visited in their local hospitals where one of us (JBW) reviewed their clinical records and interviewed and examined the patients. Patients were included in the study if they fulfilled inclusion criteria (table 1) which were designed to correspond at the time of notification to a diagnosis of acute Guillain-Barré syndrome. Since the purpose of the study was to assess prognostic factors, all patients were retained in the study even if they subsequently proved to have an atypical, relapsing or progressive course.

Standardised data sheets were employed for transfer of information to computer and to ensure uniformity. Patients were questioned about the mode of presentation of the neuropathy and particular attention paid to the dates of onset of neuropathic signs and the tempo of the ensuing functional disability. Patients were graded using a functional scale (table 2).

A standardised examination involved grading of strength according to the Medical Research Council Scale (0-5). An assessment of autonomic function was made and, where possible, measurements of nerve conduction performed. Blood was taken for immunological tests which will be reported separately.

The clinical examination and disability scale were reassessed, approximately 3,12 and 52 weeks after entry to the study. The time to improve each grade on the disability scale was recorded. Information from the notes was used in addition to the patient's account to calculate these dates as accurately as possible. Where appropriate, doctors, nurses, physiotherapists and occupational therapists were interviewed to improve the accuracy of follow up data. Complications intervening in the clinical course of each study patient were recorded.

The disability grades at 3 and 12 months were used to 
Table 1 Inclusion criteria

1 Progressive weakness of more than one limb thought to be due to neuropathy.

2 Absent reflexes in more than one limb or reduced reflexes if accompanied by electrophysiological evidence of demyelinating neuropathy, ie maximum motor conduction velocity $<40 \mathrm{~m} / \mathrm{s}$ in the forearm, and $<30 \mathrm{~m} / \mathrm{s}$ in the leg, or a decrement of the muscle action potential of $>25 \%$ elicited by a proximal compared with a distal site of stimulation.

3 Onset of neuropathic symptoms less than 2 months before notification.

4 No other identifiable cause such as diphtheria, carcinoma, porphyria.

Table 2 Disability scale

$0 \quad$ Healthy.

1 Minor symptoms or signs.

2 Able to walk 5 metres without assistance, walking frame or stick, but unable to do manual work including housework, shopping or gardening.

3 Able to walk 5 metres with assistance, walking frame or stick.

4 Chair or bed bound.

5 Requiring assisted ventilation for at least part of day or night.

6 Dead.

identify poor outcome groups so that the predictive value of various clinical features could be tested. Such features were assessed individually ( $\mathrm{Chi}^{2}$ test with Yates' correction for continuity) and in combination by logistic regression (using Generalised Linear Interactive Modelling). A combination of four features was chosen to create a statistical model to estimate the risk of poor outcome at 12 months (Disability grade 2 or greater) for defined clinical patient groups.

Electrophysiology Electrophysiological data were obtained from 94 of the study patients. Forty-nine patients were studied by one of us (JBW) with a portable Cadwell 5200 EMG machine at the bedside. These patients had a standardised assessment of motor and sensory conduction in upper and lower limbs. Skin surface temperature was measured with a temperature probe and limbs warmed, where necessary, to a minimum of $30^{\circ} \mathrm{C}$. The stimulus was a square wave of duration $0 \cdot 1-0 \cdot 2 \mathrm{~ms}$. Conventional bipolar surface electrodes (Medelec) were positioned over the muscle belly to record the maximum negative potential amplitude. Maximum motor conduction velocities (CV max) of median (M) and tibial (T) nerves were measured with conventional techniques. $^{23}$ The amplitude of muscle action potentials recorded over the muscle belly of abductor pollicis (APB) and abductor hallucis ( $\mathrm{AH}$ ) were measured and the latencies (DML) to both muscles recorded on distal stimulation. F wave response latencies were measured as the minimal latency of 10-15 responses (wrist or ankle) using distal antidromic motor nerve stimulation. ${ }^{4}$ The amplitude and latency to onset of antidromic sensory action potentials (SAPs) were recorded from radial and sural nerves. ${ }^{5}$ Distal latencies were converted to terminal sensory CV max for the radial nerve by dividing the distance between stimulating and recording electrodes by the terminal latency. Needle electromyography was performed on half the patients using standard concentric needle electrodes at one or two sites. Fibrillation and positive sharp waves were taken as evidence of denervation if present at two or more needle positions outside the end plate region. Similar data for 45 patients were obtained from the case records of other neurological centres.

\section{Results}

Clinical features (1) symptoms Limb weakness, an essential inclusion criterion, was present in all 100 patients. The interval from onset to greatest weakness varied from a few hours to some weeks. Maximum deficit was reached by $34 \%$ of patients within 7 days, $70 \%$ within 14 days and by $84 \%$ within 21 days after onset of their neuropathy. Deterioration stopped by one month in $92 \%$ and a further $4 \%$ continued to worsen up to 44 days before reaching a plateau phase and eventually recovering.

Three patients admitted to the study with an apparently acute neuropathy continued to deteriorate and developed a chronic progressive or relapsing inflammatory polyneuropathy. A further patient made a full recovery but relapsed one year after his first attack! These patients were retained in the study.

Numbness $(79 \%)$ and paraesthesiae $(75 \%)$ were the major sensory symptoms. Pain was experienced by $50 \%$ of patients and was usually most severe in the back or buttocks. Urinary sphincter disturbance was common (32\%). Many patients were aware of facial weakness and in two cases this was accompanied by subjective alteration in taste. Difficulty swallowing was noted by $46 \%$.

Clinical features (2) Signs The neurological deficits encountered at the investigator's first examination are listed in table 3. The most common cranial nerve abnormality was facial weakness, present in 53 and usually bilateral. The eighth nerve was never involved. Of the 13 patients with weakness of external ocular muscles 10 had complete ophthalmoplegia. In one patient bilateral vocal cord palsy preceded other cranial nerve abnormalities.

Table 3 Physical signs at first study

\begin{tabular}{lr}
\hline & $\%$ \\
\hline Limb weakness & 100 \\
$\quad$ Proximal & 49 \\
Distal & 27 \\
Global & 22 \\
Areflexia & 83 \\
Loss of vibration sense at ankles & 59 \\
Wasting of limb muscles & 56 \\
Facial weakness & 53 \\
Loss of joint position sense at toes & 52 \\
Weakness of jaw opening & 31 \\
Distal loss of light touch sensation & 26 \\
Distal loss of pin prick sensation & 22 \\
Reduced or absent gag reflex & 18 \\
Weakness of sternomastoid & 18 \\
Weakness of external ocular muscles & 13 \\
Tongue weakness & 13 \\
Papilloedema & 1 \\
\hline
\end{tabular}


Limb weakness was detected in all patients and both distal and proximal muscles were usually involved. Upper limbs were never affected alone although weakness was occasionally more severe in the arms than the legs. Wasting without other identified cause was present at the time of the first assessment in 32 patients, of whom 12 had symptoms for less than 2 weeks and six for less than one week. Forty-eight patients eventually developed wasting in the upper limbs and 51 in the lower limbs.

All tendon reflexes were lost in $83 \%$ of the patients at some-stage in the illness and $54 \%$ had two or more absent abdominal reflexes. Two patients were included in the study who retained all reflexes, but had neurophysiological evidence of demyelinating neuropathy. Five patients had at least one unequivocal extensor plantar response. In one patient this was explained by coincidental Friedreich's ataxia and in another severe papilloedema was also present. In the remaining three cases no other signs of central nervous system involvement were noted. All three had sufficient voluntary flexion of the toes to enable a flexor response to be made and re-examination in the convalescent phase revealed normal plantar responses. Two patients were considered to have limb incoordination out of proportion to their level of weakness or loss of joint position sense. Loss of sensation on examination was less common than symptoms of a sensory disturbance. Loss of modalities mediated by large fibres was more common than impairment of pin prick (table 3).

Twelve per cent of patients were still capable of walking unaided at peak disability, $7 \%$ required support, $47 \%$ were chair or bed bound. $23 \%$ of patients required ventilation at maximum deficit and went on to improve. A further $10 \%$ required ventilation but eventually died and $3 \%$ died without ever receiving assisted ventilation.

Cerebrospinal fluid The cerebrospinal fluid (CSF) protein concentration (mean $1.2 \mathrm{~g} / 1$ range $0 \cdot 1-6 \cdot 0$ ) was increased $(>0.4 \mathrm{~g} / \mathrm{l})$ in $80 \%$ of the 92 patients in whom the examination was performed. Abnormal values were more common when the sample was collected after the first week of the illness. CSF cell counts were high ( $>5$ cells $/ \mu \mathrm{l})$ in 11 of patients. The .median count for these patients was $8 / \mu$ l, range 6 to $103 / \mu \mathrm{l}$. The timing of CSF examination in this group was the same as in patients in whom normal cell counts were found.

Clinical course Follow-up examinations showed the expected improvement in the majority of patients but 13 patients died and 19 were still disabled at the end of one year (fig). One patient with residual disability due to Friedreich's ataxia and three who emigrated were excluded from this analysis. The most common cause of death was cardiac arrest (table 4) usually

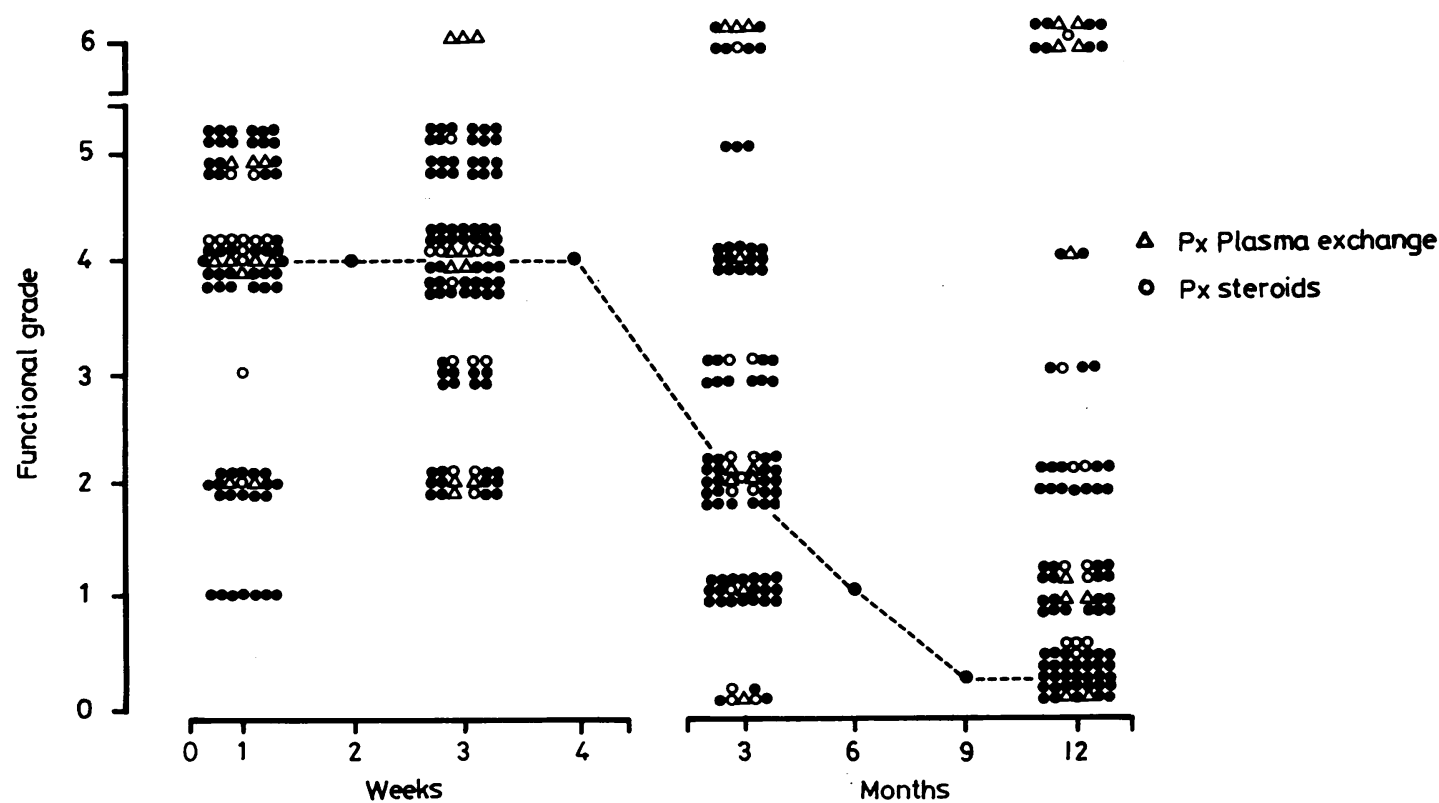

Fig The functional grades (defined in table 2) of the study patients are represented over 12 months. Patients receiving plasma exchange or steroids are distinguished. Grades have been deduced from assessments and historical data so that disability is represented at fixed intervals from onset of the neuropathy. The dotted line joins median values for each time interval. 
Table 4 Characteristics of patients who died within 12 months of onset of Guillaine-Barré syndrome

\begin{tabular}{|c|c|c|c|c|c|}
\hline Age (yr) & Ventilation & $\begin{array}{l}\text { Abd. poll. brev } \\
M A P(m V)\end{array}$ & $\begin{array}{l}\text { Interval onset } \\
\text { to grade } 4 \text { (days) }\end{array}$ & $\begin{array}{l}\text { Major cause } \\
\text { of death }\end{array}$ & $\begin{array}{l}\text { Interval from } \\
\text { onset (weeks) }\end{array}$ \\
\hline $\begin{array}{l}59 \\
73 \\
62 \\
74 \\
78 \\
72 \\
78 \\
76 \\
58 \\
66 \\
67 \\
63 \\
50\end{array}$ & $\begin{array}{l}+ \\
+ \\
+ \\
0 \\
0 \\
+ \\
+ \\
+ \\
+ \\
+ \\
+ \\
0 \\
0\end{array}$ & $\begin{array}{l}0 \\
0 \\
0 \\
- \\
1 \\
0.6 \\
1.7 \\
0.5 \\
1.3 \\
0 \\
- \\
- \\
2.5\end{array}$ & $\begin{array}{r}1 \\
2 \\
4 \\
2 \\
1 \\
5 \\
6 \\
0 \\
1 \\
3 \\
1 \\
44 \\
2\end{array}$ & $\begin{array}{l}\text { Cardiac arrest } \\
\text { Cardiac arrest } \\
\text { Chest infection } \\
\text { Pulmonary embolus } \\
\text { Chest infection } \\
\text { Renal failure } \\
\text { Respiratory failure } \\
\text { Cardiac arrest } \\
\text { Cardiac arrest } \\
\text { Chest infection } \\
\text { Aortic aneurysm } \\
\text { Suicide* } \\
\text { Pancreatic carcinoma }\end{array}$ & $\begin{array}{r}52 \\
4 \\
7 \\
1 \\
5 \\
2 \\
4 \\
5 \\
3 \\
8 \\
2 \\
40 \\
49\end{array}$ \\
\hline
\end{tabular}

*Disability grade 2 at time of death.

preceded by erratic fluctuations of pulse and blood pressure and attributed to autonomic disturbances associated with Guillain-Barré syndrome. One patient had a cardiac arrest due to accidental hypoxaemia while being ventilated but was successfully resuscitated. Ten out of the 13 deaths appeared to be a direct consequence of the neuropathy. Non fatal complications included chest infections in 22 patients, pulmonary embolus in three, deep vein thrombosis without embolism in five, and urinary tract infection following catheterisation in 11 . Hyponatraemia (sodium < $139 \mathrm{mmol} / \mathrm{l}$ ) was noticed in 12 patients but plasma and urine osmolarities were not measured.

Treatment The study was performed before the

Table 5 Clinical features of study patients associated with outcome at 3 months

\begin{tabular}{lllr}
\hline $\begin{array}{l}\text { Three month outcome } \\
\text { Disability grade }\end{array}$ & $\begin{array}{l}\text { Poor } \\
\geqslant 4\end{array}$ & \multicolumn{1}{l}{$\begin{array}{l}\text { Good } \\
\leqslant 3\end{array}$} & \multicolumn{1}{c}{ Chi $^{2}$} \\
\hline Requirement for ventilation & $18 / 23$ & $15 / 76$ & $24 \cdot 6 \ddagger$ \\
Grade 4 in $<4$ days & $19 / 23$ & $27 / 59$ & $7 \cdot 7 \dagger$ \\
Grade 4 in $<7$ days & $23 / 23$ & $23 / 59$ & $10 \cdot 6 \dagger$ \\
Peak grade < 10 days & $18 / 23$ & $32 / 76$ & $7 \cdot 8 \dagger$ \\
Age > 40 years & $20 / 23$ & $43 / 76$ & $5 \cdot 8^{*}$ \\
Blood white cells > 12000/ul & $12 / 22$ & $13 / 72$ & $9 \cdot 7 \dagger$ \\
Sedimentation rate >15 mm/hour & $11 / 11$ & $25 / 59$ & $10 \cdot 1 \dagger$ \\
Tendon reflexes retained & $0 / 23$ & $16 / 76$ & $4 \cdot 3^{*}$ \\
\hline
\end{tabular}

${ }^{*} \mathrm{p}<0.05,+\mathrm{p}<0.01, \pm \mathrm{p}<0.001$.

Table 6 Clinical features examined for an association with outcome at 12 months

\begin{tabular}{|c|c|c|c|}
\hline $\begin{array}{l}\text { Outcome at } 12 \text { months } \\
\text { Disability grade }\end{array}$ & $\begin{array}{l}\text { Poor } \\
\geqslant 2\end{array}$ & $\begin{array}{l}\text { Good } \\
1 \text { or } 0\end{array}$ & $C h i^{2}$ \\
\hline $\begin{array}{l}\text { Requirement for ventilation } \\
\text { Age } \geqslant 40 \text { years } \\
\text { Reaching disability grade } 4 \text { or worse } \\
\text { Disability grade } 4 \text { reached in } 4 \text { days } \\
\text { Muscle wasting }(<28 \text { days }) \\
\text { Time to improvement }>21 \text { days } \\
\text { Tendon reflexes retained } \\
\text { Female sex }\end{array}$ & $\begin{array}{r}19 / 32 \\
28 / 32 \\
32 / 32 \\
24 / 32 \\
14 / 27 \\
19 / 32 \\
0 / 32 \\
15 / 32\end{array}$ & $\begin{array}{l}14 / 64 \\
34 / 64 \\
47 / 64 \\
22 / 48 \\
13 / 51 \\
29 / 64 \\
16 / 64 \\
22 / 67\end{array}$ & $\begin{array}{l}11 \cdot 7 \ddagger \\
9 \cdot 6 \dagger \\
8.6 \dagger \\
5 \cdot 5^{\star} \\
6 \cdot 8 \dagger \\
2.7 \mathrm{NS} \\
7 \cdot 9 \dagger \\
1.3 \mathrm{NS}\end{array}$ \\
\hline
\end{tabular}

results of the trials of plasma exchange in GuillainBarré syndrome were available. Only 10 patients received plasma exchange, 12 prednisolone 30-60 mgms daily and two intravenous methyl prednisolone (in one to treat a lung complication). Patients treated with plasma exchange or steroids have been distinguished with different symbols in the fig and were included in the analysis of features influencing outcome.

Clinical features and outcome Poor outcome was defined in two ways, prolonged disability confining the patient to bed (disability grade 4 or greater after 3 months) or inability to perform manual work aftee 12 months (disability grade 2 or greater). The main. features associated with still being bed-bound at $\$$ months were requirement for ventilation, rapid development of inability to walk and evidence of inflammation from the peripheral blood white cell count and sedimentation rate (table 5). The main features associated with inability to undertake manual work after one year also included a requirement for ventilation and a rapid onset of inability to walk but the inflammatory features in the peripheral blood at onset were not significantly associated with poor outcome according to this criterion (table 6). No significant correlation was seen with sensory deficit (pin prick, light touch, joint position sense or vibration sense), incontinence, facial weakness, sex, or CSF findings (protein or cell count).

Correlation between electrophysiological features and outcome There was a significant association between poor outcome and small amplitude of the action potential evoked in abductor pollicis brevis by stimulation of the median nerve at the wrist (table 7). Slowed motor conduction in the forearm segment of the median nerve was also more common in patients with a poor outcome whereas the other electrophysiological measurements were not valuable in predicting outcome. The results of the electrophysiological studies performed by one of the authors according to a uniform protocol were similar to those 
Table 7 Association of electrophysiological measurements and outcome at 3 and 12 months

\begin{tabular}{|c|c|c|c|c|c|c|}
\hline \multirow[b]{2}{*}{$\begin{array}{l}\text { Outcome } \\
\text { Disability grade }\end{array}$} & \multicolumn{3}{|c|}{3 months } & \multicolumn{3}{|c|}{12 months } \\
\hline & $\begin{array}{l}\text { Poor } \\
\geqslant 4\end{array}$ & $\begin{array}{l}\text { Good } \\
\leqslant 3\end{array}$ & $C h i^{2}$ & $\begin{array}{l}\text { Poor } \\
\geqslant 2\end{array}$ & $\underset{0-1}{\text { Good }}$ & $C h i^{2}$ \\
\hline 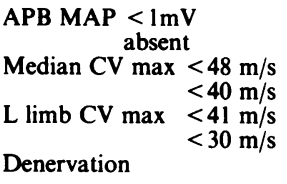 & $\begin{array}{r}10 / 18 \\
6 / 18 \\
7 / 10 \\
6 / 10 \\
7 / 9 \\
1 / 9 \\
4 / 15\end{array}$ & $\begin{array}{r}8 / 53 \\
1 / 53 \\
31 / 58 \\
19 / 58 \\
31 / 48 \\
10 / 48 \\
10 / 40\end{array}$ & $\begin{array}{c}9.6 \dagger \\
11.6 \ddagger \\
0.4 \\
1.7 \\
0.1 \\
0.1 \\
0.1\end{array}$ & $\begin{array}{r}11 / 24 \\
6 / 24 \\
12 / 18 \\
11 / 18 \\
10 / 14 \\
2 / 14 \\
5 / 20\end{array}$ & $\begin{array}{r}7 / 45 \\
1 / 45 \\
26 / 48 \\
14 / 48 \\
28 / 43 \\
9 / 43 \\
8 / 35\end{array}$ & $\begin{array}{l}5 \cdot 9^{*} \\
6 \cdot 6^{*} \\
0 \cdot 4^{*} \\
4 \cdot 4^{*} \\
0 \cdot 3 \\
0 \cdot 0 \\
0 \cdot 0\end{array}$ \\
\hline
\end{tabular}

${ }^{*} \mathrm{p}<0.05,+\mathrm{p}<0.01, \pm \mathrm{p}<0.001$.

of the whole series. The relationship between slowing of median motor $\mathrm{CV}$ max below $40 \mathrm{~m} / \mathrm{s}$ was even more significant. Such marked slowing was exhibited by six out of seven patients with a poor outcome at 12 months but only by four out of 30 with a good outcome $(\mathrm{p}<0.001)$.

Abnormal $\mathrm{F}$ wave latencies were the most common electrophysiological abnormality occurring in $90 \%$ of lower limb examinations but provided only poor discrimination between patients destined to have a poor or good outcome at either 3 or 12 months.

Prediction of outcome Our analysis of predictive factors was focused on outcome at 12 months since such persistent disability usually has a more profound overall effect on a patient than severe deficit after 3 months which eventually resolves completely. The patient with Friedreich's ataxia was excluded because his disability was not due to Guillain-Barré syndrome. Three patients who had achieved a good outcome by

Table 8 Relative risks of poor outcome at 12 months attributable to the four most discriminating variables

\begin{tabular}{lll}
\hline & $\begin{array}{l}\text { Relative } \\
\text { risk }\end{array}$ & $\begin{array}{l}95 \% \text { confidence } \\
\text { intervals }\end{array}$ \\
\hline Age $\geqslant 40$ years & 4.4 & $1 \cdot 2-16.4$ \\
Disability grade 4 in $\leqslant 4$ days & $3 \cdot 1$ & $1.0-9.6$ \\
Requiring ventilation & 2.6 & $0.9-7.6$ \\
APB MAP $\leqslant 1 \mathrm{mV}$ & 3.8 & $1.0-14.0$ \\
\hline
\end{tabular}

Table 9 Predicted probabilities of poor outcome at 12 months in percentages using the four most discriminating variables

\begin{tabular}{|c|c|c|c|c|}
\hline & \multicolumn{2}{|c|}{ Bedbound 0-4 days } & \multicolumn{2}{|c|}{ Bedbound $>4$ days } \\
\hline & Age $<40 y r$ & Age $\geqslant 40 y r$ & Age $<40 y r$ & Age $\geqslant 40 y r$ \\
\hline $\begin{array}{l}\text { MAP APB } \\
\leqslant 1 \mathrm{mv} \\
\text { Not ventilated } \\
\text { Ventilated }\end{array}$ & $\begin{array}{l}36 \\
59\end{array}$ & $\begin{array}{l}71 \\
86\end{array}$ & $\begin{array}{l}15 \\
31\end{array}$ & $\begin{array}{l}44 \\
67\end{array}$ \\
\hline $\begin{array}{l}\text { MAP APB } \\
>1 \mathrm{mv} \\
\text { Not ventilated } \\
\text { Ventilated }\end{array}$ & $\begin{array}{l}12 \\
27\end{array}$ & $\begin{array}{l}39 \\
62\end{array}$ & $\begin{array}{r}4 \\
11\end{array}$ & $\begin{array}{l}17 \\
34\end{array}$ \\
\hline
\end{tabular}

three months but could not be contacted at 12 months were included in the good outcome group. Seventeen patients had such mild disease that they never lost the ability to walk unaided and these all fell into the good outcome group. Since they never reached the criterion for poor outcome they were excluded from further analysis. All the patients that died were included in the poor outcome group. Logistic regression analysis of different clinical features on outcome was therefore performed on a total of 82 patients of whom 77 had had electrophysiological measurements. The relative risks of poor outcome attributable to the four important discriminating variables (table 8 ) and the estimated probability of poor outcome are represented in table form (table 9).

\section{Discussion}

Several retrospective studies have sought to identify clinical and laboratory features that might correlate with outcome. Unfortunately the number of patients with a poor prognosis is small in any individual study which makes it difficult to define any characteristics that might separate these patients from the majority. Osler and Sidell ${ }^{7}$ suggested that patients with a strictly motor neuropathy and no sphincter disturbance were more likely to have a benign prognosis and described 10 cases which followed that pattern. They recommended strict adherence to the diagnostic features of Guillain, Barré and Strohl's original cases. Marshall ${ }^{8}$ described 35 patients including some with severe sensory loss or sphincter disturbance and could find no evidence that such features influenced outcome adversely. A particularly severe motor deficit appears to carry a geater risk of residual disability according to a number of authors. ${ }^{9-11}$ Two paediatric studies have suggested that the time taken to improve also has prognostic value. $^{1213}$ Eberle and colleagues $^{12}$ examined the case records of 47 children referred to a rehabilitation unit for factors that might correlate with the degree of eventual recovery. They concluded that an interval of greater than 18 days from maximum deficit to onset of improvement was associated 
with incomplete recovery in a large number of patients. Other factors more common in the poor outcome group were absence of tendon reflexes from onset, severe weakness in the distal muscles and curiously a relatively low CSF protein. This latter feature may be an artifact, since the majority of studies ${ }^{14-16}$ have failed to find any correlation between CSF protein and outcome. Normal or relatively low CSF protein measurements are not unusual in the first week of the illness ${ }^{17}$ and it is possible that more severe cases are admitted and have a lumbar puncture sooner.

Although Osler and Sidell ${ }^{7}$ considered that a CSF pleocytosis predicted a relatively poor outcome, we and most other authors did not find that the presence of cells in the CSF was a significant prognostic factor. $^{81416}$

In this study outcome at both 3 and 12 months was strongly influenced by the severity of peak deficit and its speed of progression. Patients who became tetraplegic rapidly had a significantly greater chance of lasting disability. This may reflect the severity of the inflammatory response in the nerves, which if more severe would be likely to cause intraneural oedema, raised endoneurial pressure and axonal damage. In accord with this idea two indices of systemic inflammation, peripheral blood white cell count and sedimentation rate, were more often abnormal in those patients with poor outcome at 3 months. Ropper ${ }^{19}$ has recently drawn attention to a subgroup of patients with hyperacute Guillain-Barré syndrome who have a poor outcome.

The best measure of the speed of progression of the disease appeared to be the duration of the neuropathy before walking became impossible. This interval was easier to measure than the time taken to reach peak deficit, which can only be determined after the peak deficit has occurred and is often uncertain. The 32 patients in the poor outcome group at 12 months, are largely accounted for by the 28 who reached grade 4 within 7 days. Three others relapsed or developed chronic progressive neuropathy. Only one patient with a true monophasic disease and poor outcome would not have been identified by this measure of outcome alone.

The latency from onset of neuropathy until improvement began was not useful in predicting outcome. This conclusion conflicts with previous observations in which patients taking longer than 3 weeks to improve had significantly more residual sequelae. ${ }^{20}$ The onset of improvement is difficult to measure accurately since minor fluctuations in neurological examination may be caused by intercurrent infections or disturbances of mood and not followed by sustained improvement. The duration of the plateau phase, which is subject to the same difficulties in accurate determination, similarly failed to show a significant correlation with outcome. An interval of greater than 2 months until improvement of one disability grade did indicate a greater chance of lasting disability, but cannot be used to predict outcome at an early stage.

Several authors have noted the association of severe muscular wasting with subsequent poor outcome. ${ }^{918}$ Wasting eventually developed in all our surviving patients with poor outcome. Very early wasting (within 14 days) was seen in a few patients with subsequent poor outcome but its presence was not statistically significant. By 28 days after onset of symptoms, the presence of wasting was significantly more common in the patients who eventually had a poor outcome. This feature does not help predict outcome at the really acute stage when intervention with treatment regimes such as plama exchange is being considered.

The electrophysiological abnormalities found in our patients were similar to those previously reported. ${ }^{182122}$ Of our patients $56 \%$ had slowed upper limb, and $68 \%$ slowed lower limb motor nerve conduction. Proximal conduction was more commonly affected as indicated by abnormalities in $\mathrm{F}$ wave conduction at the wrist in $83 \%$. Many patients had significant reductions in the amplitude of sensory action potentials and slowing of sensory conduction, especially later in their illness. Only two electrophysiological features appeared to have an important bearing on outcome. These were the compound? muscle action potential of abductor pollicis brevis evoked by stimulation of the median nerve at the wrist and a markedly slowed upper limb conduction velocity. A grossly reduced or absent compound muscle action potential in abductor pollicis brevis alone would identify about one third of the patients with a poor outcome after 12 months. The measurements of muscle action potentials were obtained with conventional bipolar surface electrodes used routinely for conduction studies. Although every attempt was made to achieve the optimum electrode position this method is less reliable than the use of a single electrode placed over the muscle belly with a reference electrode placed over the tendon. This could not have been a disadvantage when no evoked potential was seen. It was this abnormality which had the greatest prognostic importance.

If an evoked muscle action potential is absent it is not possible to be certain whether demyelination with complete conduction block or axonal degeneration is responsible. Where muscle action potentials could be recorded but were very small $(>1 \mathrm{mV})$, dispersion of the potential indicated that conduction block was at least partly responsible for the reduced amplitude. However, the presence of wasting shows that axonal 
degeneration was an important pathological feature in the poor outcome patients. The pathology of a recent case of acute axonal neuropathy has been described $^{24}$ and there is evidence of a correlation between very small distally recorded compound muscle action potentials and the subsequent development of fibrillation. ${ }^{23}$

Spontaneous fibrillation was associated with poor outcome in a number of previous studies. ${ }^{151621}$ In one of these studies ${ }^{21} 13$ of 19 patients with spontaneous fibrillation showed no signs of recovery after 2 months in hospital and 17 had muscle atrophy. Only limited sampling of muscles was performed in most of our patients and examinations were usually performed within the first 3 weeks, before fibrillation has usually appeared. ${ }^{22}$

A weak but significant association existed between the median nerve motor conduction velocity in the acute stage and eventual outcome. Abnormalities in lower limb conduction did not appear to have any prognostic value. A few studies have found conduction measurements to be of some value in predicting outcome $\mathrm{e}^{152526}$ but others have found no consistent correlation. ${ }^{21} 27$ This present study indicates a low relative risk attributable to slowed upper limb conduction so that a small study with relatively few poor outcome patients would be likely to miss an effect of this magnitude.

We managed to recruit 86 of our 100 patients from within the Thames Regions among a population of 13.7 million. We have attempted to recruit as many patients with Guillain-Barre syndrome as possible from a given study area so that any bias from patterns of referral might be reduced. If we assume an incidence of Guillain-Barré syndrome of no more than 1.9 cases per 100,00 population ${ }^{28}$ then we might have expected a maximum of 264 cases. This suggests a case ascertainment of at least $33 \%$. We recognise that this ascertainment is incomplete but the outcome of this study group is more likely to be representative of the prognosis of Guillain-Barré syndrome patients in general than a study based on the experience of a single institution.

Ten patients who died during the first 12 weeks of the illness have been included in the modelling analysis. It is possible that features influencing death (such as autonomic disturbance) might be different from those influencing residual disability so that some of the patients that died might have been destined to make a good recovery. This seems very unlikely for the three patients that died late in the course of their illness since they retained significant residual disability up to the time of death. In order to exclude any bias introduced by excluding these 10 patients we repeated the analysis with the early deaths removed. No significant difference in the results was obtained and the same four features emerged as having major prognostic importance, although the adverse effect of requiring ventilation was reduced.

A statistical model was constructed from the variables of predictive value (table 8 ) which was derived from the 82 patients who became bedbound. The validity of this model will have to be tested on a fresh population of patients with acute idiopathic neuropathy. The accuracy of prediction derived from one set of data would be expected to be less good when applied to new sets of data, particularly when a large number of variables have been used to calculate predicted probabilities since the results become tailored to the data from whence they were derived. Relatively few variables were used to create our model in order to reduce such errors.

JBW was a Williams Research Fellow of the University of London at the time of the study. We thank the Multiple Sclerosis Society of Great Britain for financial support.

We thank the patients themselves and the following physicians who allowed us to study their patients: Prof DJP Barker, Dr MA Barrie, Dr PI Biggs, Dr JN Blau, Dr GW Bradley, Dr C Clarke, Dr R Clifford-Jones, Dr CJ Earl, Dr LJ Findley, Prof. RW Gilliatt, Dr R Greenwood, Dr P Harper, Dr PKP Harvey, Dr G Harwood, Dr AP Hopkins, Dr LS Illis, Dr J Jestico, Dr GF Joplin, Dr C Kennard, Dr R Kocen, Dr LS Lange, Dr AJ Lees, Dr N Leigh, Dr B Macdougall, Dr W Mallinson, Dr J Marigold, Dr HM Mather, Dr J Morgan-Hughes, Dr P Munro, Prof. J Newsom-Davis, Dr EA Nieman, Dr MD O'Brien, Dr JD Parkes, Dr GD Perkin, Dr JE Rees, Dr PJ Rees, Dr EH Reynolds, Dr AH Roberts, Dr CI Roberts, Prof R Robinson, Dr P Rudge, Dr M Sarner, Dr JW Scadding, Dr J Sewell, Prof PK Thomas, Dr AM Turner, Dr P Trend, Dr M Wiles, Dr J Wilson, Dr LA Wilson.

We are grateful to Professor J Newsom-Davis, DR J Payan, Dr N Murray, Dr M J G Harrison, Dr D Coggan and Professor D J P Barker, for helpful advice.

\section{References}

1 Hughes RAC, Winer JB. Guillain-Barré syndrome. In: Mathews WB, Glaser, GH, eds. Recent Advances in Clinical Neurology 4. Edinburgh: Churchill Livingstone, 1984;19-49.

2 Thomas PK, Sears TA, Gilliatt RW. The range of conduction velocity in normal motor nerve fibres to the small muscles of the hand and foot. J Neurol Neurosurg Psychiatry 1959;22: 175-81.

3 Ludin HP. In: Electromyography in practice. New York: Springer Verlag, 1980:40-1.

4 Kimura J, Butzer JF. F-Wave conduction velocity in GuillainBarré syndrome. Arch Neurol 1975;32:524-29.

5 Critchlow JF, Seybold ME, Jablecki CJ. The superficial radial nerve: techniques for evaluation. $J$ Neurol Neurosurg Psychiatry 1980;43:929-33. 
6 Guillof RJ. Peripheral nerve conduction in Miller Fisher syndrome. J Neurol Neurosurg Psychiatry 1977;40:801-7.

7 Osler ID, Sidell AD. The Guillain-Barre syndrome: the need for exact diagnostic criteria. $N$ Engl J Med 1960;262:964-9.

8 Marshall J. The Landry-Guillain-Barré syndrome. Brain 1963; 86:56-66.

9 Loffel NB, Rossi LN, Mumenthaler M, Lutschg J, Ludin HP. The Landry-Guillain-Barré syndrome-complications, prognosis and natural history in 123 cases. $J$ Neurol Sci 1977;33: 71-9.

10 Peterman AF, Daly DD, Dion FR, Keith HM. Infectious neuronitis (Guillain-Barré syndrome) in children. Neurology 1959; 9:533-9.

11 Pleasure DE, Lovelace RE. The prognosis of acute polyradiculoneuritis. Neurology 1969;18:1143-8.

12 Eberle E, Brink J, Azen J, White D. Early predictors of incomplete recovery in children with Guillain-Barré polyneuritis. J Pediatr 1975;86:356-9.

13 Rossi LN, Mumenthaler M, Lutschg J, Ludin HP. Guillain-Barré syndrome in children with special reference to the natural history of 38 personal cases. Neuropadiatrie 1976;7:42-51.

14 Ravn H. The Landry-Guillain-Barré syndrome. A survey and clinical report of 127 cases. Acta Neurol Scand 1967;43 (suppl 30): $1-64$.

15 Eisen A, Humphreys P. The Guillain-Barré syndrome. A clinical and electrodiagnostic study of 25 cases. Arch Neurol 1974;30: 438-43.

16 Mcleod JG. Electrophysiological studies in the Guillain-Barre syndrome. Ann Neurol 1981;9(suppl):20-7.

17 Wiederholt HM, Mulder DW, Lambert EH. The LandryGuillain-Barré Strohl syndrome of poly-radiculoneuropathy -historical review, report on 97 patients and present concepts. Proc Mayo Clin 1964;39:427-51.

18 Mcleod JG, Walsh JC, Prineas JW, Pollard D. Acute idiopathic polyneuritis. A clinical and electrophysiological study. J Neurol Sci 1976;27:145-62.

19 Ropper AH. Severe acute Guillain-Barré syndrome. Neurology 1986;36:429-32.

20 Winer JB, Hughes RAC, Greenwood R, Healy MH. Prognosis in the Guillain-Barre syndrome. Lancet 1985;i:1202-3.

21 Raman PT, Taori GM. Prognostic significance of electrodiagnostic studies in the Guillain-Barré syndrome. $J$ Neurol Neurosurg Psychiatry 1976:39:163-70.

22 Albers JW, Donofrio PD, McGonagle TK. Sequential electrodiagnostic abnormalities in acute inflammatory demyelinating polyradiculoneuropathy. Muscle Nerve 1985;8:528-39.

23 Brown WF, Feasby TE. Conduction block and denervation in Guillain-Barré polyneuropathy. Brain 1984;107:219-39.

24 Feasby TE, Gilbert JJ, Brown WF, Bolton CF, Hahn AF, Koopman WJ, Zochodne DW. An acute axonal form of Guillain-Barré polyneuropathy. Brain 1986;109:1115-26.

25 Takeuchi H, Takahashi M, Kang J, Ueno S, Yamada A, Miki H. The Guillain-Barré syndrome; clinical and electroneuromyographic studies. $J$ Neurol 1984;231:6-10.

26 Hausmanowa-Petrusewicz I, Emeryk B, Rowinska-Marcinoska $\mathrm{K}$, Jedrzejowska $\mathbf{H}$. Nerve conduction in the Guillain-BarréStrohl syndrome. J Neurol 1979;220:169-84.

27 Prineas JW, Mcleod JG. Chronic relapsing polyneuritis. J Neurol Sci 1975;27:427-58.

28 Larsen J, Kvale G, Nyland H. Epidemiology of the GuillainBarré syndrome in the county of Horderland, Western Norway. Acta Neurol Scand 1985;71:43-47. 